Slavica

bruxellensia

\section{Slavica bruxellensia}

Revue polyphonique de littérature, culture et histoire

slaves

$11 \mid 2015$

Littérature et philosophie

\title{
Agata Stankowska, Żeby nie widzieć oczu zapatrzonych w nic-o twórczości Czesława Miłosza
}

\section{Małgorzata Wardecka}

\section{(2) OpenEdition}

\section{Journals}

Édition électronique

URL : http://journals.openedition.org/slavica/1691

DOI : 10.4000/slavica.1691

ISSN : 2034-6395

\section{Éditeur}

Université libre de Bruxelles - ULB

\section{Référence électronique}

Małgorzata Wardecka, « Agata Stankowska, Żeby nie widzieć oczu zapatrzonych w nic - o twórczości Czesława Miłosza », Slavica bruxellensia [En ligne], 11 | 2015, mis en ligne le 10 février 2015, consulté le 22 septembre 2020. URL : http://journals.openedition.org/slavica/1691 ; DOI : https://doi.org/ 10.4000/slavica.1691

Ce document a été généré automatiquement le 22 septembre 2020.

\section{cc)}

Les contenus de Slavica bruxellensia sont mis à disposition selon les termes de la Licence Creative Commons Attribution - Pas d'Utilisation Commerciale - Pas de Modification 3.0 France. 


\section{Agata Stankowska, Żeby nie widzieć oczu zapatrzonych w nic - o twórczości Czesława Miłosza}

Małgorzata Wardecka

\section{RÉFÉRENCE}

Stankowska A., Żeby nie widzieć oczu zapatrzonych w nic - o twórczości Czesława Miłosza (Pour ne pas voir les yeux observant le vide - sur l'oeuvre de Czesław Miłosz), wydawnictwo naukowe UAM, Poznań, 2013, 281 p. 
Lauréat du prix Nobel, traducteur, poète et prosateur, Czesław Miłosz (1911-2004) est une personnalité fondamentale pour tout amateur de la littérature polonaise. Ses œuvres ont joué un rôle primordial tout au long du $\mathrm{XX}^{\mathrm{e}}$ siècle et leur aspect multidimensionnel impressionne toujours un grand nombre de lecteurs.

Agata Stankowska, l'auteure de Żeby nie widzieć oczu zapatrzonych $w$ nic - o twórczości Czesława Miłosza a divisé son ouvrage en deux parties, Myśli $i$ słowa (Pensées et mots) suivi de Prologi $i$ dialogi (Prologues et dialogues), et ce dans le but de mieux appréhender la sagesse de vie de

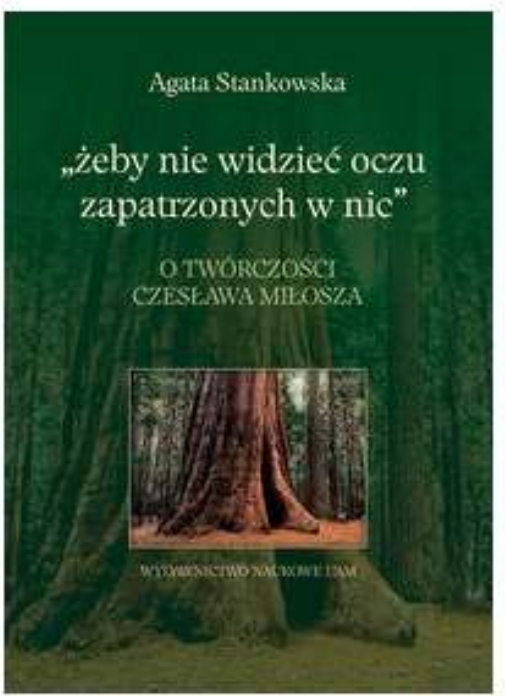
cet écrivain. Il s'agit avant tout de suivre la logique des contradictions qui est le fil conducteur de ce livre. En effet, selon Miłosz, chaque être vit dans une antinomie, déchiré entre les "vérités de ses ancêtres » et la «science de la contemporanéité ». La seule manière pour lui de dépasser ce déchirement serait de diriger son regard vers ce qui remplit de joie par sa simplicité d'être. Il est important de souligner que Stankowska a composé son ouvrage selon l'antagonisme déjà apparu dans le recueil d'essais de Miłosz, Ziemia Ulro ${ }^{1}$ (La Terre d'Ulro), où il est question d'une cassure de la civilisation européenne en conséquence de la domination du rationalisme, de l'humanisme laïque et des courants eschatologiques, catastrophistes. Malgré ses recherches étendues l'auteure n'est toutefois pas satisfaite du résultat et dans sa conclusion elle avertit le lecteur de la complexité et de la polyvalence des écrits de l'écrivain.

Læ première partie se compose de quatre thématiques, quatre questions auxquelles Stankowska tente de fournir une réponse : Miłosz - gnotsyk? (Miłosz - un gnostique ?), Miłosz - klasyk? (Miłosz - un classique ?), Miłosz - realista? (Miłosz - un réaliste ?), Miłosz - antymodernista? (Miłosz - un antimoderniste ?). Elle retrace les sujets mis en avant par l'écrivain tout au long de son parcours littéraire: les inspirations religieuses, le choix entre vie et "végétation existentielle ", le monde tragique et sa division, la recherche du sens de la vie, la mort. Par une analyse approfondie des ouvrages de Miłosz, l'auteure essaie d'explorer avec rigueur la pensée, l'art de la parole et le procédé que suit Miłosz en tant que « gardien de l'industrie de la poésie polonaise ".

Dans la seconde moitié du livre, l'attention est portée sur la correspondance de Miłosz échangée avec ses contemporains, Aleksander Wat et Osip Mandelsztam. Stankowska compare méticuleusement leurs compositions littéraires, découvre comment s'est formée leur conscience poétique au fil du temps et l'impact de l'Histoire sur leurs œuvres. Afin de mieux expliquer au lecteur leurs relations ambiguës, elle entreprend également d'ajouter des commentaires aux extraits des lettres proposées.

Ce livre à vocation scientifique cible avant tout celles et ceux qui ont déjà trouvé une clé de compréhension de l’œuvre de Czesław Miłosz. Żeby nie widzieć oczu 
zapatrzonych w nic - o twórczości Czesława Miłosza est un nouvel outil qui invitera ces lecteurs à déceler les nombreuses contradictions et antinomies du monde littéraire de cet incontournable écrivain polonais.

\section{NOTES}

1. Miłosz Cz., Ziemia Ulro, Instytut Literacki, Paris, 1977. Edition française: La terre d'Ulro. Méditation sur l'espace et la religion, Albin Michel, Paris, 1996.

\section{AUTEURS}

\section{MALGORZATA WARDECKA}

Etudiante de Master européen ULB/Université de Varsovie 